\title{
CONTRIBUIÇÕES DE PROJETOS GLOBALIZADORES NA PROMOÇÃO DA EDUCAÇÃO SOCIOAMBIENTAL
}

\author{
Manoela Schneider Sachet ${ }^{1}$ \\ Natalia Aparecida Soares ${ }^{2}$
}

Resumo: O presente estudo buscou analisar as potencialidades de um projeto globalizador de Educação Socioambiental (ESA), com ênfase nas problemáticas socioambientais locais, para o desenvolvimento de um pensar complexo e sistêmico no contexto do ensino formal. Para a sistematização da pesquisa dentro do projeto globalizador foram aplicados questionários e realizadas atividades com alunos de uma escola privada do município de Novo Hamburgo/RS. Os dados obtidos apontam que as práticas globalizadas de ESA desempenham papel fundamental na formação cidadã, contribuindo para religar e ampliar saberes e estimulando o desenvolvimento do pensamento complexo.

Palavras-chave: Práticas Educativas; Problemáticas Socioambientais; Enfoque Globalizador.

Abstract: The present study investigates the potential of a holistic project of Socio-environmental Education (SEE), with emphasis on local socioenvironmental issues, to the development of a complex and systemic thinking in the context of formal education. To systematize the research within the holistic project, questionnaires were applied and activities were carried out with students from a private school in the city of Novo Hamburgo/RS. The data obtained indicate that the SEE holistic practices play a key role in civic education, contributing to rewire and expand knowledge and stimulating the development of complex thinking.

Keywords: Educational Practices; Socio-environmental Problems; Holistic Approach.

\footnotetext{
1 Universidade Feevale. E-mail: manoelas@feevale.br

2 Universidade Feevale. E-mail: nataliasoares@feevale.br
} 


\section{Introdução}

Diante da emergência de uma crise socioambiental mundial, a educação tornou-se um dos principais alicerces para incitar a construção de uma sociedade mais sustentável, pautada na formação de indivíduos conscientes em escala local e global, com uma visão integradora. Nesse sentido, destaca-se a necessidade do desenvolvimento da Educação Socioambiental (ESA), a fim de instigar os educandos a repensar as relações entre sociedade e natureza.

A ESA atua dentro do contexto ambiental e histórico-social de cada sociedade e permite novas aproximações entre os diferentes conhecimentos, de modo a promover a compreensão da complexidade das inter-relações que permeiam as questões socioambientais (GUIMARÃES, 2015; CÓRDULA; NASCIMENTO, 2013; CARVALHO, 2012). Sob essa perspectiva, oferece um ensino reflexivo, crítico, globalizado, interdisciplinar e participativo, propiciando aos sujeitos o entendimento, o envolvimento e a intervenção nessas questões.

Desse modo, a promoção da educação socioambiental no âmbito escolar faz-se cada vez mais urgente, já que ela aproxima os educandos do contexto em que vivem e possibilita que, através de práticas globalizadas, deparem-se com situações reais e mobilizem seus conhecimentos para interpretar tais problemas em sua origem, propondo soluções que possam modificar este meio, desenvolvendo, assim, a cidadania.

O presente estudo buscou através de uma pesquisa qualitativa e exploratória, alinhada ao desenvolvimento de um projeto globalizador com enfoque nas problemáticas socioambientais, seguindo recomendações de Zabala (2002), analisar as potencialidades de um projeto globalizador de Educação Socioambiental, com ênfase nas problemáticas locais, para 0 desenvolvimento de um pensar complexo e sistêmico no contexto do ensino formal.

O referido projeto globalizador foi desenvolvido com alunos do $8^{\circ}$ ano do ensino fundamental, de uma escola privada do município de Novo Hamburgo/RS, entre os meses de agosto a setembro de 2020, partindo-se do seguinte questionamento: quais as potencialidades e contribuições de um projeto globalizador para o desenvolvimento de práticas socioambientais com alunos dos anos finais do ensino fundamental?

\section{A complexidade no ensino por trás das questões socioambientais}

O ensino de Ciências é uma área formada por diversos campos do saber, atuando de modo relevante na construção e no aprimoramento dos conhecimentos articulados com a realidade, como o meio ambiente, a saúde, a tecnologia e a sociedade.

Nas diretrizes curriculares brasileiras, a temática da Educação 
Parâmetros Curriculares Nacionais (PCN). Esses temas apresentavam um enfoque flexível e contextualizado, e a EA buscava a formação de "[...] cidadãos conscientes, aptos a decidir e a atuar na realidade socioambiental de um modo comprometido com a vida, com o bem-estar de cada um e da sociedade, local e global' (BRASIL, 1997, p. 25). Com a homologação da Base Nacional Comum Curricular (BNCC) em 2018, a promoção da EA foi assegurada nos Temas Contemporâneos Transversais (TCTs), objetivando uma abordagem contextualizada e integradora, que forneça aos sujeitos a compreensão dos diversos elementos que compõem e afetam a vida em sociedade, contribuindo, assim, na formação de cidadãos (BRASIL, 2019).

Pesquisadores como Guimarães (2015), Carvalho (2012) e Ruscheinsky (2002) defendem que a EA deve ser abordada sob os vieses da complexidade e da interdisciplinaridade, tratando questões socioambientais e visando mudanças comportamentais e éticas nos sujeitos. Este mesmo aspecto é ressaltado nas Diretrizes Curriculares Nacionais para a Educação Ambiental, que reafirmam o papel transformador e emancipatório da EA e estimulam 0 fortalecimento da cidadania, da consciência crítica e da participação individual e coletiva sobre a dimensão socioambiental (BRASIL, 2012).

Abordar questões socioambientais demanda considerar a teia de relações estabelecidas entre os contextos cultural, econômico, político, social e natural e todas as suas interações complexas $e$ interdependentes (GUIMARÃES, 2015; CARVALHO, 2012). Nesse contexto, Carvalho (2012) salienta que o desenvolvimento de práticas socioambientais

[...] implica atitude de investigação atenta, curiosa, aberta à observação das múltiplas inter-relações e dimensões da realidade [...], construir um conhecimento dialógico, ouvir os diferentes saberes, tanto os científicos quanto os outros saberes sociais (locais, tradicionais, das gerações, artísticos, poéticos, etc.) (p. 133).

Sob essa perspectiva, a Educação Socioambiental orienta-se por uma prática pedagógica interdisciplinar, que visa promover uma nova concepção das relações entre homem e natureza, permeando a complexidade.

A ideia de complexidade é apresentada por Morin (2007) como uma atitude voltada à interligação e à comunicação de vários campos do saber, almejando uma ampliação da visão de mundo.

Perpassando a complexidade, Morin (2007) então aponta para a necessidade de uma reforma no pensamento. $O$ autor sugere substituir um modo de pensar que fragmenta e isola a adotar um modo de pensar complexo, que reúne e globaliza os diferentes conhecimentos. Isso não significa que o pensamento linear deve ser descartado, mas reconhecer a necessidade de 
considerar a insuficiência de um pensamento isolado, seja ele simplificador ou complexo (MORIN, 2007 apud SOARES; FARIAS, 2017, p. 36).

Logo, a tarefa do pensamento complexo é permitir a religação e a integração dos saberes, considerando a multiplicidade e as unidades.

Morin (2007) pondera que, para promover uma reforma no pensamento, primeiramente se deve promover uma reforma no ensino. $\mathrm{O}$ autor propõe a aprendizagem da religação e da problematização, ensejando o desenvolvimento de uma educação globalizada:

Devemos 'ecologizar' as disciplinas, isto é, levar em conta tudo o que lhe é contextual, aí compreendidas as condições culturais e sociais. É necessário que vejamos em que contexto elas nascem, como colocam seus problemas [...] (MORIN, 2007, p. 51).

Assim, uma reforma na educação requer modificar, sobretudo, os métodos de ensino e as disciplinas. Para Zabala (2002),

[...] a organização dos conteúdos deve permitir o estudo de uma realidade que sempre é complexa e em cuja aprendizagem é preciso estabelecer o máximo de relações possíveis entre os diferentes conteúdos que são aprendidos para potencializar sua capacidade explicativa (p. 35).

A realidade complexa passa a ser então, o objeto prioritário de estudo e de conhecimento. O aluno torna-se sujeito ativo e protagonista do seu processo de aprendizagem, e as disciplinas devem ser os meios de ampliar e aprofundar os conhecimentos sobre a realidade, oferecendo estratégias que possibilitem o entendimento e a intervenção social.

Quando a opção educativa é a do conhecimento para a ação crítica, o ensino deve orientar-se para propor um saber complexo, [...] uma formação que facilite uma visão mais complexa e crítica do mundo, superadora das limitações próprias de um conhecimento parcelado e fragmentado que, sabemos, é inútil para enfrentar a complexidade dos problemas reais do ser humano. Um conhecimento que seja global, integrador, contextualizado, sistêmico, capaz de enfrentar as questões e os problemas abertos e difusos que a realidade coloca (ZABALA, 2002, p. 58). 
Diante disso, Zabala (2002) destaca o enfoque globalizador como uma prática pedagógica do ensino para a complexidade. Esse método consiste na abordagem de temas que são parte da realidade dos educandos, no qual a organização dos conteúdos acontece de maneira significativa, promovendo um intercâmbio entre as disciplinas e utilizando diversos instrumentos de conhecimento. $\mathrm{O}$ autor explica que:

O enfoque globalizador pretende desenvolver no aluno e na aluna um pensamento complexo que Ihe permita identificar 0 alcance de cada um dos problemas que lhe coloca a intervenção na realidade e escolher os diferentes instrumentos conceituais e metodológicos de qualquer um dos diferentes campos do saber que, independentemente de sua procedência, relacionando-os ou integrando-os, ajudem-no a resolvê-los (p. 36).

Déjardin (2016, p. 82) lembra que "[...] a complexidade da realidade em que se vive inclui princípios, noções e modos de se refletir sobre o exercício individual e coletivo da cidadania, emergindo as contradições e potencialidades de cada sujeito nesse processo formativo".

Para Leff (2009), o pensamento da complexidade ambiental instiga a construção de uma nova realidade, através do diálogo entre seres e saberes distintos.

A pedagogia da complexidade ambiental reconhece que apreender o mundo parte do ser de cada sujeito, de seu ser humano; essa aprendizagem consiste em um processo dialógico que transborda toda racionalidade comunicativa construída sobre a base de um possível consenso de sentidos e verdades. Além de uma pedagogia do ambiente, que volta seu olhar ao entorno, à história e à cultura do sujeito, a fim de reapropriar seu mundo desde suas realidades empíricas, a pedagogia ambiental reconhece o conhecimento; observa o mundo como potência e possibilidade; entende a realidade como construção social, mobilizada por valores, interesses e utopias (LEFF, 2009, p. 20, grifo do autor).

O desenvolvimento do pensamento complexo é atingido através da compreensão, da contextualização e da religação de todos esses conhecimentos (MORIN, 2007). Zabala (2002) corrobora dizendo que "somente é possivel atuar na complexidade quando se é capaz de utilizar os diferentes instrumentos de conhecimento existentes de maneira inter-relacionada" (p. 36).

A complexidade das questões socioambientais contempla uma ampla gama de métodos para abordá-las através do ensino formal. A 
interdisciplinaridade abrangida por essas questões torna-as passíveis de articulação, aproximação e do desenvolvimento de práticas envolvendo múltiplos saberes (CARVALHO, 2012), permitindo aos sujeitos identificar e entender os problemas socioambientais para intervir na comunidade.

Diversas pesquisas (SIERRA, 2017; CÓRDULA; NASCIMENTO, 2013; SILVA; LOPES; DANTAS, 2013; TAVARES, 2010) apontam que a abordagem de problemáticas socioambientais locais promove a reflexão e a sensibilização dos alunos, contribuindo para que os sujeitos adquiram habilidades para compreender e intervir no mundo ao seu redor.

$\mathrm{Na}$ esfera da complexidade, Soares e Farias (2017) constataram que as práticas educativas e socioambientais desenvolvidas em um centro de Educação Ambiental possibilitaram transformar as percepções e os saberes socioambientais dos alunos, tornando-os significativos e promovendo uma forma de pensar global e contextualizada.

Caramello (2012), em sua pesquisa, confirmou que a temática socioambiental é abordada nas escolas através da veiculação de informações midiáticas, pautada no currículo linear. Para a autora (2012), essa abordagem

[...] conduz a uma visão sobre os problemas socioambientais limitada, seja porque não dá a oportunidade para os alunos se posicionarem pautados numa perspectiva próxima de sua realidade ou porque não explicita elementos do discurso escolar e científico capazes de tratar o problema complexo em questão (p. 5-6).

Em síntese, o desafio de ensinar para a complexidade implica em problematizar situações próximas dos alunos, com base em uma abordagem global, sistêmica e integradora. Nesse viés, a (ir) racionalidade complexa da Educação Socioambiental e todas as suas interações mútuas, intrínsecas e interdependentes entre os âmbitos social e ambiental abrem espaço para a intervenção a partir de um enfoque globalizador.

Com isso, a promoção de ações e práticas globalizadas de educação socioambiental visa sensibilizar, conscientizar e ampliar as percepções dos sujeitos sobre o mundo e as suas variadas dimensões, buscando tornar a cidadania mais próxima deles e de suas realidades.

\section{Metodologia}

O presente estudo contemplou o método qualitativo-exploratório, apresentando natureza aplicada. No quesito exploratório, a referida pesquisa baseou-se na linha investigativa de pesquisa participante, pelo fato de haver interação direta da professora pesquisadora com o grupo amostral da pesquisa. 
Os instrumentos de coleta de dados consistiram na aplicação de questionários semiestruturados e no desenvolvimento de um projeto com enfoque globalizador seguindo as etapas propostas por Zabala (2002). A proposta inicial desse projeto de pesquisa contemplava a coleta de dados presencial, no entanto, devido ao Decreto Estadual no 55.292, de 04 de junho de 2020 (RIO GRANDE DO SUL, 2020), que instituiu as normas de distanciamento social controlado às instituições de ensino, a coleta de dados ocorreu de forma virtual e a interação com os discentes por meio de plataformas online disponibilizadas pela escola participante da pesquisa.

Dessa forma, o projeto foi sistematizado em cinco encontros online, com duração de 2 horas cada, realizados durante os meses de agosto e setembro de 2020, conforme Quadro 1.

Quadro 1. Plano das atividades desenvolvidas no Projeto Globalizador.

\begin{tabular}{|c|c|c|c|}
\hline Fase & $\begin{array}{l}\text { Articulações do } \\
\text { conhecimento }\end{array}$ & Estratégias desenvolvidas & Encontro \\
\hline Motivação & - & $\begin{array}{l}\text { O município de Novo Hamburgo/RS é } \\
\text { exemplo dos efeitos do processo de } \\
\text { urbanização e de crescimento } \\
\text { populacional sem planejamento. Esses } \\
\text { fatores, associados à desigualdade } \\
\text { social e ao mau planejamento ambiental } \\
\text { acarretam diversas problemáticas } \\
\text { socioambientais; além da habitação } \\
\text { irregular das áreas de risco, o município } \\
\text { também enfrenta problemas sanitários, } \\
\text { como o baixo índice de coleta de esgoto } \\
\text { e de resíduos e a dispersão do } \\
\text { mosquito Aedes aegypti. } \\
\text { Apresentação audiovisual atrelada à } \\
\text { aplicação da metodologia EVOC. }\end{array}$ & \multirow[t]{2}{*}{ Encontro 1} \\
\hline $\begin{array}{l}\text { Apresentação } \\
\text { do objeto de } \\
\text { estudo }\end{array}$ & $\begin{array}{l}\text { Ciências; } \\
\text { Geografia }\end{array}$ & $\begin{array}{l}\text { Aplicação do questionário inicial; } \\
\text { Exibição de vídeos "ONG Que Se Dane } \\
\text { (QSD) - Lixo", "Como nascem os } \\
\text { paradigmas"?; } \\
\text { Apresentação audiovisual e debate } \\
\text { sobre a relação homem/natureza. }\end{array}$ & \\
\hline $\begin{array}{c}\text { Análise e } \\
\text { explicitação } \\
\text { das questões } \\
\text { e delimitação } \\
\text { do objeto de } \\
\text { estudo }\end{array}$ & $\begin{array}{l}\text { Ciências; } \\
\text { Geografia; } \\
\text { Português }\end{array}$ & $\begin{array}{l}\text { Construção de nuvem de palavras; } \\
\text { Análise e discussão de reportagens de } \\
\text { problemáticas socioambientais do } \\
\text { município. }\end{array}$ & Encontro 2 \\
\hline
\end{tabular}

Continua... 


\begin{tabular}{|c|c|c|c|}
\hline Fase & $\begin{array}{l}\text { Articulações do } \\
\text { conhecimento }\end{array}$ & Estratégias desenvolvidas & Encontro \\
\hline $\begin{array}{l}\text { Identificação } \\
\text { dos } \\
\text { instrumentos }\end{array}$ & $\begin{array}{l}\text { Ciências; } \\
\text { Geografia; } \\
\text { Matemática }\end{array}$ & $\begin{array}{l}\text { Pesquisa e análise nos sites "Instituto } \\
\text { Trata Brasil" e "Painel Saneamento"; } \\
\text { Parte } 01 \text { da atividade "Eu repórter: } \\
\text { solucionando problemas": identificação e } \\
\text { mapeamento de problemáticas } \\
\text { socioambientais no município utilizando o } \\
\text { software Google Earth. }\end{array}$ & Encontro 3 \\
\hline $\begin{array}{l}\text { Utilização do } \\
\text { saber disciplinar }\end{array}$ & $\begin{array}{c}\text { Artes; Ciências; } \\
\text { Geografia; } \\
\text { Português }\end{array}$ & $\begin{array}{l}\text { Parte } 02 \text { da atividade "Eu repórter: } \\
\text { solucionando problemas": resolução de } \\
\text { situações-problema; } \\
\text { Parte } 03 \text { da atividade "Eu repórter: } \\
\text { solucionando problemas": confecção de } \\
\text { panfletos virtuais. }\end{array}$ & Encontro 4 \\
\hline $\begin{array}{c}\text { Conclusões, } \\
\text { generalização e } \\
\text { integração }\end{array}$ & $\begin{array}{c}\text { Artes; Ciências; } \\
\text { Geografia; } \\
\text { Português } \\
\end{array}$ & $\begin{array}{l}\text { Socialização dos panfletos virtuais e } \\
\text { confecção da cartilha. }\end{array}$ & \multirow[t]{2}{*}{ Encontro 5} \\
\hline $\begin{array}{l}\text { Visão global e } \\
\text { ampliada }\end{array}$ & - & Aplicação do questionário final. & \\
\hline
\end{tabular}

Fonte: As autoras (2020).

O grupo amostral dessa pesquisa foi composto por alunos do oitavo ano do Ensino Fundamental, de uma escola privada, localizada na área urbana de Novo Hamburgo/RS. A amostra foi constituída por 22 alunos, mas nem todos responderam aos questionários, que foram disponibilizados de forma online. A faixa etária dos discentes participantes oscila entre 13 e 14 anos.

O questionário inicial (QI) foi respondido por 22 discentes e incluiu 04 questões abertas e 01 fechada, visando identificar os conhecimentos prévios dos alunos e as suas concepções sobre meio ambiente e problemáticas socioambientais, bem como o seu nível de preocupação frente às seguintes problemáticas: descarte irregular de resíduos, tratamento de esgoto, focos de dengue, enxurrada, inundações e alagamentos, deslizamento de terra e poluição de arroios e rios.

Durante a aplicação do projeto, a coleta de dados se deu através da observação e dos registros das produções dos estudantes.

O questionário final (QF) foi aplicado ao término do projeto, e contemplou 09 questões abertas e 01 fechada, referindo-se aos conhecimentos acerca da temática abordada e às atividades desenvolvidas. Esse questionário foi respondido por 17 alunos.

A análise dos dados ocorreu de acordo com cada etapa da pesquisa, as quais estão dispostas no Quadro 2. 
Quadro 2. Relações entre as etapas da pesquisa e as metodologias utilizadas

\begin{tabular}{|l|l|}
\hline \multicolumn{1}{|c|}{ Etapas da pesquisa } & \multicolumn{1}{|c|}{ Metodologia para análise dos dados } \\
\hline Aplicação do questionário inicial & $\begin{array}{l}\text { Análise de conteúdo seguindo orientações } \\
\text { de Bardin (2011) }\end{array}$ \\
\hline $\begin{array}{l}\text { Desenvolvimento do projeto globalizador, } \\
\text { totalizando 10h/aula }\end{array}$ & $\begin{array}{l}\text { Observação direta dos alunos e das } \\
\text { produções discentes }\end{array}$ \\
\hline Aplicação do questionário final & $\begin{array}{l}\text { Análise de conteúdo seguindo orientações } \\
\text { de Bardin (2011) }\end{array}$ \\
\hline
\end{tabular}

Fonte: As autoras (2020).

Para avaliação e comparação das respostas discentes nos dois questionários foi utilizada a análise de conteúdo proposta por Bardin (2011), e para classificar as percepções dos alunos sobre meio ambiente as categorias de análise foram adaptadas de Reigota (2007), apresentadas no Quadro 3.

Quadro 3. Percepções sobre meio ambiente

\begin{tabular}{|l|l|}
\hline Conservacionista & $\begin{array}{l}\text { Evidencia apenas a ideia de conservação e preservação dos } \\
\text { recursos naturais. }\end{array}$ \\
\hline Naturalista & $\begin{array}{l}\text { Meio ambiente como sinônimo de natureza, considerando } \\
\text { fatores bióticos e/ou abióticos. }\end{array}$ \\
\hline Globalizante & Relações recíprocas entre natureza e sociedade. \\
\hline
\end{tabular}

Fonte: Adaptado de Reigota (2007).

Os dados analisados correspondem à concepção dos alunos quanto à relevância das atividades desenvolvidas e às suas percepções sobre questões específicas abordadas no projeto, buscando identificar as potencialidades e contribuições dessas práticas no desenvolvimento do pensamento complexo e de uma ESA efetiva.

\section{Resultados e discussão}

Entender as percepções socioambientais dos educandos foi de suma importância para a intervenção, a partir de um enfoque globalizador acerca das problemáticas socioambientais locais.

Ressaltamos que o grupo participante dessa pesquisa provém de uma instituição de ensino que possui uma metodologia participativa, voltada ao desenvolvimento de projetos interdisciplinares, que perpassam aspectos naturais e sociais, de modo que os estudantes estão habituados a discutir e refletir criticamente.

Por se tratar de um projeto com enfoque globalizador, participaram paralelamente dos encontros, docentes da referida instituição das disciplinas de Artes, Ciências, Geografia, Inglês e Matemática. Os professores 
acompanharam a realização das atividades e promoveram articulações com suas respectivas áreas do conhecimento.

Optamos por organizar os dados em duas categorias: análise comparativa das percepções discentes e análise das estratégias desenvolvidas no projeto globalizador. As respostas dos alunos estão codificadas por $A(N)$, onde $(\mathrm{N})$ equivale a um número atribuído para cada aluno.

\section{Análise comparativa das percepções discentes}

O primeiro questionamento realizado buscou verificar as percepções dos alunos sobre meio ambiente. A Figura 1 apresenta as percepções do conceito de meio ambiente segundo as categorias adaptadas de Reigota (2007).

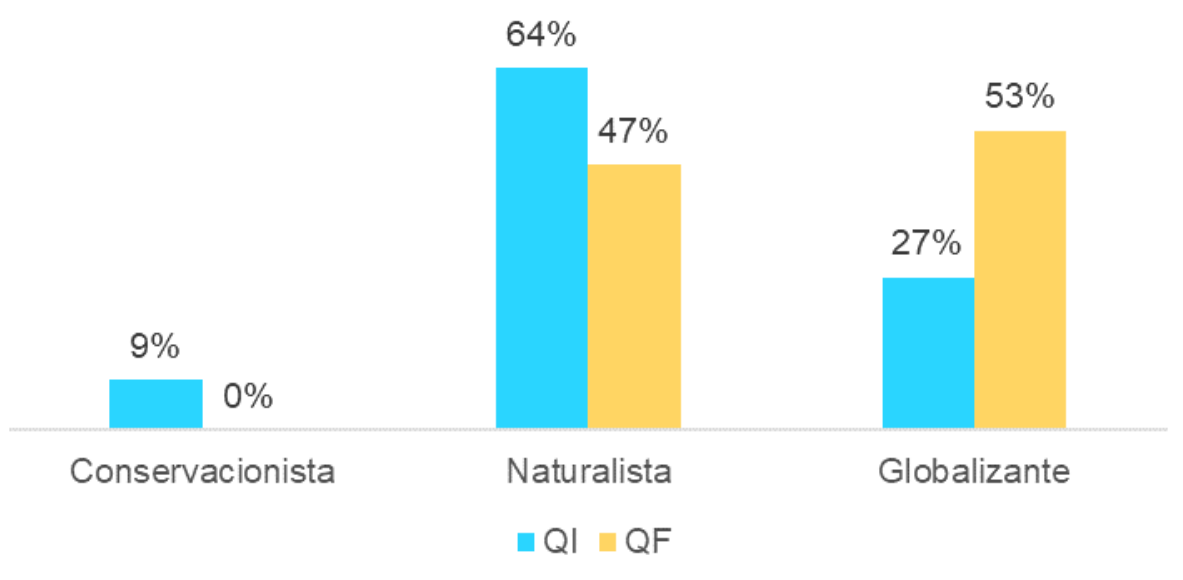

Figura 1: Percepções discentes sobre meio ambiente.

Fonte: As autoras (2020).

Os resultados obtidos no QI evidenciam o predomínio da visão naturalista, implícita em $64 \%$ das respostas, como as seguintes:

(A19): "Uma parte que eu lembro é a fauna e a flora".

(A22): "Meio ambiente define as coisas não vivas e vivas da natureza. A natureza define o meio ambiente"!

Observa-se nas respostas dos estudantes que a maioria não relaciona a presença do homem na visão predominante de meio ambiente. Oenning e Carniatto (2011) e Morin (2007), enfatizam que a visão naturalista demonstra a prevalência de um modo de pensar fragmentado, que desintegra o ser humano desse meio e não considera a multidimensionalidade das relações estabelecidas com a natureza.

Para Reigota (2007), a visão naturalista confunde o conceito de meio ambiente com o de ecossistema, não incluindo o ser humano e suas ações dentro do meio ambiente. Sobre isso, Oenning e Carniatto (2011) dizem que 
essa confusão é comum, uma vez que vários discursos, imagens e expressões veiculadas pela mídia associam meio ambiente à ideia de natureza pura.

Os dados do QF indicam que a amostra exibiu mudanças no conceito de meio ambiente: a percepção conservacionista apresentou um decréscimo de $9 \%$ no questionário inicial para $0 \%$ no questionário final; a percepção naturalista também diminuiu, mas ainda se fez presente em $47 \%$ das respostas. Segundo Bezerra e Gonçalves (2007, p. 124), a transição entre o senso comum para uma concepção mais elaborada de meio ambiente é complexa, tendo em vista que os interesses políticos, econômicos e sociais são conflitantes.

Destacamos, sobretudo, a mudança para percepções mais próximas da globalizante, aparecendo em $53 \%$ das respostas do questionário final, como por exemplo:

(A11): "O meio ambiente é onde vivemos, onde os animais vivem. Muitos humanos estão estragando ele, com fábricas poluentes, desmatamento, ..."

(A16): "Todo o espaço que está ao nosso redor, a natureza, algo que tem seus próprios organismos e sua própria maneira de agir; são as ruas, os prédios, as árvores; é um todo que está além do nosso alcance, mas que pode ser afetado e destruído, assim como tudo o que existe".

Tais conceitos atentam para uma visão conjunta de sociedade e natureza, percebendo o homem como um dos integrantes do meio, ao passo em que relacionam essa interação e, principalmente, os seus impactos negativos no ambiente.

Compreender as relações de troca com o meio, estabelecer relações entre o contexto local e global, perceber os efeitos da ação antrópica na interação com a natureza contribuiu para que os discentes transformassem suas percepções sobre meio ambiente, inserindo o ser humano dentro dele. À vista disso, Guimarães (2015) considera que a promoção da ESA postula em seus objetivos a sensibilização, a ação para a transformação da realidade e a ampliação da consciência do educando sobre a relação integrada do ser humano com a natureza.

Visando o aprofundamento do tema, os discentes foram questionados sobre suas percepções acerca dos problemas socioambientais. Durante a análise do QI observamos que o grupo amostral já apresentava conhecimentos prévios, como evidenciado nas respostas expressas pelos discentes A14 e A21:

(A14): "Conflitos da sociedade com o meio ambiente".

(A21): "São alterações sofridas pelo meio ambiente". 
As respostas do QF demonstram uma ampliação nas percepções acerca do tema, reforçando que a ação antrópica é, atualmente, a principal causa dos problemas socioambientais:

(A7): "Tudo o que prejudica o meio ambiente, poluição, desmatamento, queimadas, e a maioria desses problemas as vezes é causado por nós mesmo, tudo isso afeta nossa fauna, flora, rios, solo".

(A21): "São problemas enfrentados pela população, pelo descarte incorreto de lixo e ações inadequadas do homem".

Para Sauvé (2005), a lacuna existente entre o ser humano e a natureza está na origem desses problemas. Da mesma forma, Giacometti e Dominschek (2018) enfatizam que "[...] o ser humano desligou-se da natureza como se esta não fizesse parte de sua existência, o mesmo esqueceu que somos coadunados a ela através de nossa origem, somos parte e necessitamos dela [...]' (p. 146).

As respostas de A7 e A21 revelam o desenvolvimento de concepções mais elaboradas, considerando o caráter de causa e consequência e estabelecendo inter-relações entre o todo e seus componentes.

Para avaliar o nível de preocupação dos estudantes frente aos problemas socioambientais, comumente verificados no município de Novo Hamburgo/RS, foram atribuídos valores às respostas no modelo de escala Likert, com índices que variam de 1 (nada preocupado) a 5 (totalmente preocupado). As médias do nível de preocupação dos alunos nos dois questionários estão dispostas na Figura 2.

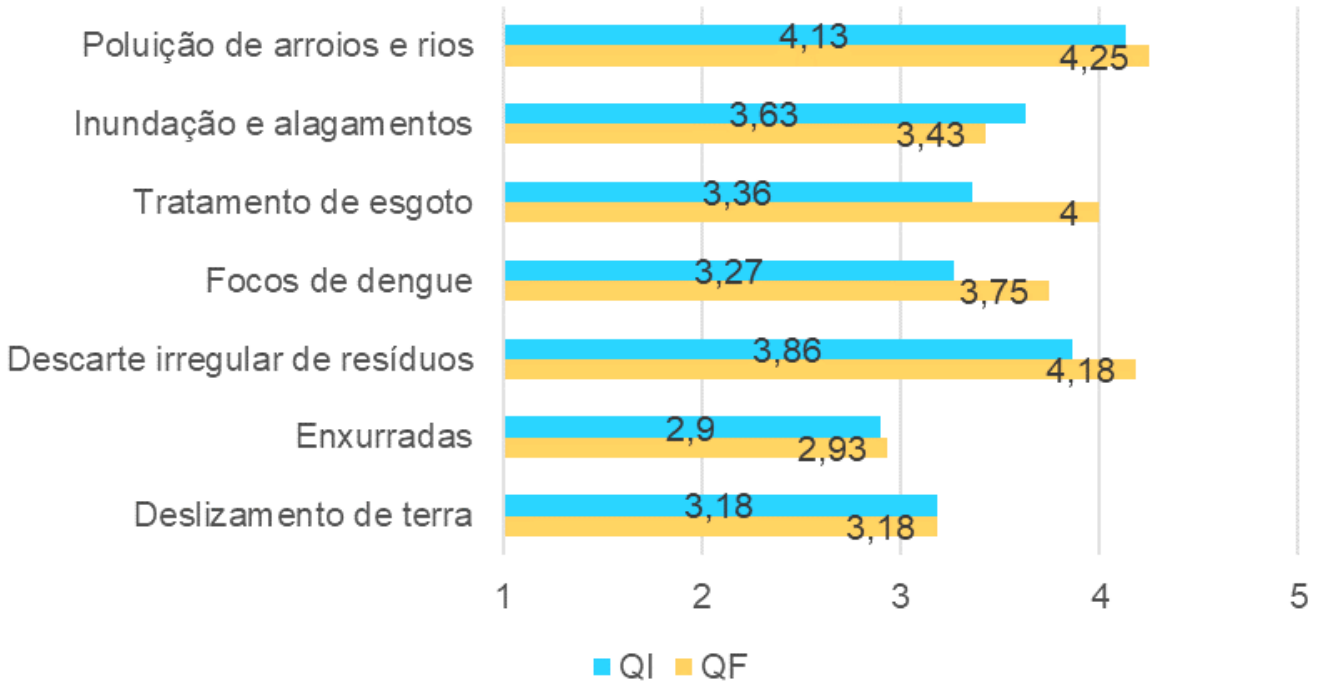

Figura 2: Nível de preocupação dos discentes acerca das problemáticas socioambientais.

Fonte: As autoras (2020). 
De modo geral, a análise comparativa do nível de preocupação dos alunos revela que as estratégias desenvolvidas ampliaram a sensibilização e conscientização dos indivíduos frente aos problemas socioambientais. Silva, Lopes e Dantas (2013), também verificaram essa mesma potencialidade na promoção de práticas contextualizadas de ESA.

Ressaltamos alguns comentários dos alunos ao longo dos encontros:

(A13): "Tem fatores que estão muito piores do que eu imaginava, como os esgotos de NH".

(A6): “[...] não basta só falarmos do meio ambiente e não agir. Pensando no presente e no futuro, se não melhorarmos, será que mais para frente ainda teremos o meio ambiente"?

(A21): "A cidade de Novo Hamburgo precisa evoluir muito ainda, porque temos cada vez mais problemas com enchentes, deslizamentos, focos de dengue e lixo em local indevido".

Entretanto, verificou-se uma relação entre o nível de preocupação dos alunos e a proximidade de cada problemática com a realidade deles: as menores médias foram constatadas em problemas menos recorrentes nos bairros onde reside o grupo amostral. Por outro lado, o aumento significativo do nível de preocupação dos alunos com "descarte irregular de resíduos" e "tratamento de esgoto", aponta para o desenvolvimento de uma atitude mais observadora e crítica dos discentes, bem como para a tomada de consciência acerca dos problemas mais corriqueiros, que foram percebidos no decorrer dos encontros e na análise das produções discentes.

Além disso, percebemos que os problemas socioambientais mais observados pelos alunos durante o projeto, ora na análise de reportagens e sites, ora no mapeamento e identificação de problemáticas nos bairros do município, apresentaram aumento no nível de preocupação discente. Já o nível de preocupação frente aos problemas menos evidenciados apresentou um pequeno decréscimo ou se manteve estável.

Este resultado atribui-se à frequência com que os problemas são verificados pelos alunos no cotidiano como também, pelas discussões e debates promovidos por meio desse projeto globalizador, que despertou um olhar mais sistêmico e globalizante acerca de tais problemáticas.

\section{Análise das estratégias desenvolvidas no projeto globalizador}

O projeto com enfoque globalizador foi concretizado através de atividades interdisciplinares que permitiram a investigação do meio, a fim de despertar a preocupação dos estudantes com as questões socioambientais, em favor da construção de uma consciência planetária. As estratégias buscaram desenvolver habilidades de análise, discussão, identificação, resolução e 
informação acerca das problemáticas, visando incitar a reflexão e a ação para a transformação da realidade socioambiental.

Para identificar a visão dos alunos sobre as estratégias desenvolvidas durante o projeto, foi realizado o seguinte questionamento: "A partir das experiências obtidas neste projeto, quais foram as atividades mais significativas para você? Justifique sua resposta".

As respostas dos alunos indicaram que $62 \%$ consideram a atividade "Eu repórter: solucionando problemas" como a mais relevante; $15 \%$ indicou o debate das relações homem/natureza; outros $15 \%$ apreciaram todas as atividades e $8 \%$ considerou a análise e discussão das reportagens trazidas pela professora-pesquisadora.

As justificativas dos alunos quanto à significância da atividade "Eu repórter" correspondem à resolução de situações-problema e à confecção de panfletos virtuais:

(A16): "A parte 2 da atividade 'Eu Repórter', pois achei as questões e a proposta muito bem elaboradas e pude realmente refletir e dar o meu melhor para realizá-la."

(A21): "Gostei bastante da atividade em que fomos repórteres e a que fizemos os folhetos, pois vimos como há coisas ruins e boas em nossos bairros e que também iremos informar outras pessoas com os folhetos".

Segundo Khoiriyah e Husamah (2018), a resolução de situaçõesproblema "incentiva os alunos a construir seus próprios conhecimentos através de problemas reais que requerem uma resolução" ( $p$. 156, tradução nossa). Essa estratégia, portanto, busca formar alunos críticos e questionadores, capazes de aplicar o conhecimento escolar nas situações da vida cotidiana (SIERRA, 2017, p. 23).

Percebe-se que o aluno A21 sustenta seu argumento fazendo referência à qualidade informativa da cartilha e dos panfletos virtuais (Figura 3) e ao caráter multiplicador da ESA, considerando o contexto local e a sua participação como ator social aprendente e ensinante. Nesse sentido, Carvalho (2012) diz que a formação dos indivíduos deve ser pensada dentro da responsabilidade com os outros e com o ambiente, contribuindo no processo de humanização e conscientização dos sujeitos, numa perspectiva crítica e transformadora. 


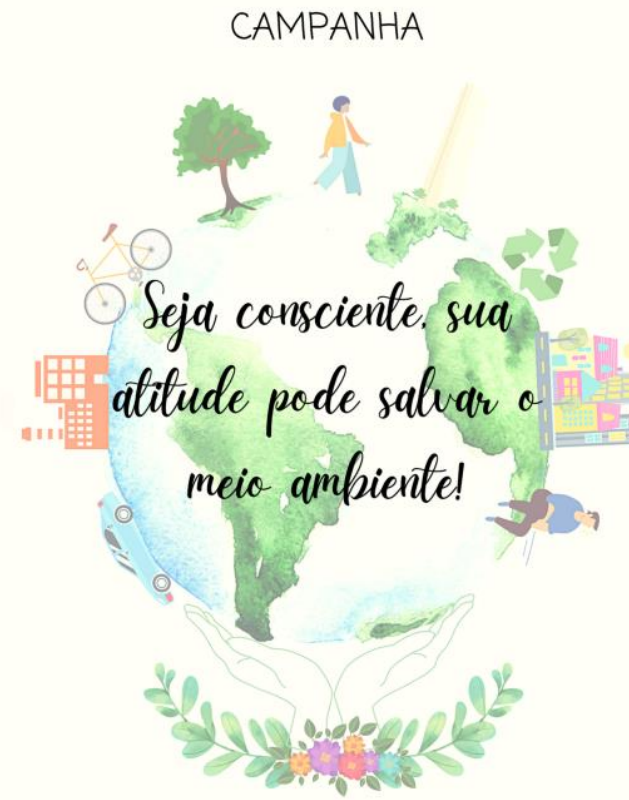

FEEVALE

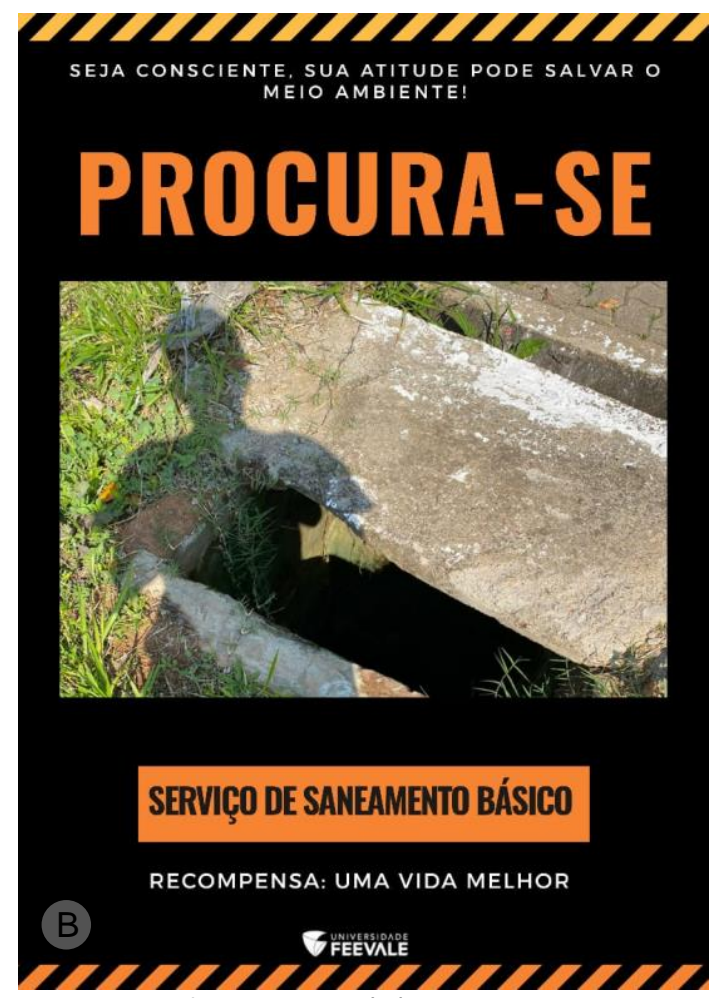

A

Figura 3: Vista da cartilha (A) e de um panfleto virtual (B).

Fonte: Produções discentes realizadas durante o projeto globalizador (2020).

Do mesmo modo, os alunos foram questionados sobre as estratégias menos significativas: $55 \%$ indicaram ter apreciado todas as atividades propostas. Destacamos o comentário de A9: "Acho que todas as experiências foram significativas, pois sempre que aprendemos algo novo é algo significativo.". No entanto, $18 \%$ indicaram a discussão da relação homem/natureza como a atividade menos significativa; $11 \%$ indicaram a análise e discussão de reportagens; $8 \%$ indicou a confecção de panfletos virtuais e outros $8 \%$ a resolução de situações-problema.

Os aspectos supracitados vão de encontro ao envolvimento dos estudantes nas atividades propostas, tendo em vista que esses demonstraram menor envolvimento nas discussões promovidas e maior envolvimento na realização de atividades com características de aprendizagem ativa e dinamicidade.

\section{Considerações finais}

A Educação Socioambiental permite o entendimento das relações intrínsecas e sistêmicas que perpassam as questões socioambientais. Tão logo, fomenta discussões e reflexões críticas sobre as relações complexas, visando desenvolver novas percepções no ser humano sobre sua 
responsabilidade individual e planetária, a fim de promover mudanças nos valores e nas atitudes dos indivíduos.

Entende-se que esta prática pedagógica se potencializa através de uma abordagem integradora, que abrange a promoção de práticas globalizadas e interdisciplinares, pensadas dentro do contexto local.

Apesar de ser uma estratégia proposta dentro de um curto espaço de tempo, a análise comparativa dos dados coletados aponta que, após a realização do projeto, grande parte dos alunos desenvolveu percepções globalizantes e mais próximas da complexidade, pois consideram o ser humano como parte do meio ambiente, compreendem as interações que ocorrem entre ser humano e natureza e estabelecem relações de causa e consequência em torno dessas interações.

Conforme proposto no objetivo da referida pesquisa, a promoção de práticas contextualizadas de ESA contribuiu para reconstruir, transformar e ampliar percepções discentes sobre meio ambiente e problemáticas socioambientais, além de sensibilizá-los frente aos problemas que a realidade apresenta.

Dessa forma, compreendemos que os projetos globalizadores constituem um importante instrumento para promover a ESA no âmbito escolar, desempenhando papel fundamental na formação cidadã e na religação dos conhecimentos cotidianos e científicos, apresentando significativo potencial para estimular o pensamento complexo dos alunos dentro do contexto formal.

\section{Referências}

BARDIN, L. Análise de conteúdo. São Paulo: Edições 70, 2011.

BEZERRA, T. M. O.; GONÇALVES, A. A. C. Concepções de meio ambiente e educação ambiental por professores da Escola Agrotécnica Federal de Vitória de Santo Antão-PE. Biotemas. v. 20, n. 3, set. 2007, p. 115-125.

BRASIL. Base Nacional Comum Curricular (BNCC): Temas Contemporâneos Transversais na BNCC: Contexto Histórico e Pressupostos Pedagógicos. Brasília: MEC, 2019. Disponível em: <http://basenacional comum.mec.gov.br/images/implementacao/contextualizacao temas contempor aneos.pdf >. Acesso em: 09 set. 2020.

BRASIL. Ministério da Educação. Conselho Nacional de Educação. Resolução CNE/CP no 2, de 15 de junho de 2012. Estabelece as Diretrizes Curriculares Nacionais para a Educação Ambiental. Diário Oficial da União, Brasília, DF, 18 jun. 2012. Disponível em: <http://portal.mec.gov.br/dmdocuments/ rcp002 12.pdf>. Acesso em: 18 jul. 2020.

BRASIL. Parâmetros Curriculares Nacionais (PCN): Temas Transversais: Meio Ambiente e Saúde. Brasília: MEC/SEF, 1997. Disponível em: $<$ http://portal.mec.gov.br/seb/arquivos/pdf/ivro091.pdf>. Acesso em: $21 \mathrm{dez}$. 2019.

Revbea, São Paulo, V. 16, № 4: 287-304, 2021. 
CARAMELLO, G. W. Aspectos da complexidade: contribuições da Física para compreensão do tema ambiental. 2012. Tese (Doutorado em Ensino de Ciências) - Universidade de São Paulo, São Paulo, 2012. Disponível em: $<$ https://teses.usp.br/teses/disponiveis/81/81131/tde-13082012-

104627/publico/Giselle Watanabe Caramello.pdf>. Acesso em: 24 mai. 2020.

CARVALHO, I. C. M. Educação ambiental: a formação do sujeito ecológico. 6 ed. São Paulo: Cortez, 2012.

CÓRDULA, E. B. L.; NASCIMENTO, G. C. C. Educação Socioambiental: Um caminho para uma sociedade sustentável. Revista Científica da Faculdade de Educação e Meio Ambiente. v. 4, n. 1, p. 18-26, jan-jun, 2013.

DÉJARDIN, I. A importância da sustentabilidade e da Educação Ambiental nas discussões sobre a problemática socioambiental da cidadania em escolas públicas. Revista Brasileira de Educação Ambiental. São Paulo, v. 11, n. 5, p. 67-88, 2016.

GIACOMETTI, K.; DOMINSCHEK, D. L. Ações antrópicas e impactos ambientais: industrialização e globalização. Caderno Intersaberes, v. 7, n.10, 2018.

GUIMARÃES, M. A dimensão ambiental na educação. 12 ed. Campinas: Papirus, 2015.

KHOIRIYAH, A. J.; HUSAMAH, H. Problem-based learning: Creative thinking skills, problem-solving skills, and learning outcome of seventh grade students. JPBI (Jurnal Pendidikan Biologi Indonesia), v. 4, n. 2, p. 151-160, 2018.

LEFF, E. Complexidade, racionalidade ambiental e diálogo de saberes. Educação \& Realidade, v. 34, n. 3, p. 17-24, set-dez 2009.

MORIN, E. Educação e complexidade: os sete saberes e outros ensaios. 4 ed. São Paulo: Cortez, 2007.

OENNING, V.; CARNIATTO, I. Implicações das representações sociais de meio ambiente na relação homem-natureza para a educação ambiental: um estudo a partir das definições de alunos moradores da zona rural do Paraná. Educação Ambiental em AÇÃo, n. 38, dez. 2011-fev. 2012.

REIGOTA, M. Meio ambiente e representação social. 7. ed. São Paulo: Cortez, 2007.

RIO GRANDE DO SUL. Decreto $\mathbf{n}^{\circ}$. 55.292, de 04 de junho de 2020. Assembleia Legislativa, DOE n.. 113, 2a edição, de 4 de junho de 2020. Disponível em: <https://www.legisweb.com.br/legislacao/?id=396531>. Acesso em 07 ago. 2020.

RUSCHEINSKY, A. Educação ambiental: abordagens múltiplas. Porto Alegre: Artmed, 2002.

SAUVÉ, L. Educação ambiental: possibilidades e limitações. Educação e Pesquisa, São Paulo, v. 31, n. 2, p. 317-322, mai-ago. 2005. 
SIERRA, C. L. C. O Ensino de Ciências por Resolução de Problemas: uma proposta aplicada a estudantes do Ensino Fundamental da cidade de Araucária. 2017. Dissertação (Mestrado - Mestrado em Ensino de Ciências) Universidade Tecnológica Federal do Paraná, Curitiba, 2017. Disponível em: $<$ http://riut.utfpr.edu.br/jspui/bitstream/1/2545/1/CT PPGFCET M Sierra\%2c\% 20Cristine\%20Lois\%20Coleti 2017.pdf>. Acesso em: 29 dez. 2019.

SILVA, C. O.; LOPES, J. P.; DANTAS, M. I. Coleta seletiva e reciclagem do lixo: experiência de Educação Socioambiental em uma escola da rede estadual de ensino de Maceió, Alagoas. Nature and Conservation, v. 6, n. 2, p. 26-42, mai-out 2013.

SOARES, N. A.; FARIAS, M. E. O Centro de Educação Ambiental Augusto Kampff: uma experiência como difusor de práticas educativas e socioambientais buscando o Pensamento Complexo. 2017. Tese (Doutorado em Ensino de Ciências e Matemática) - Universidade Luterana do Brasil, Canoas, $2017 . \quad$ Disponível em: $<$ http://www.ppgecim.ulbra.br/teses/index.php/ppgecim/article/view/296/297>. Acesso em: 16 mai. 2020.

TAVARES, L. J. Educação Ambiental na escola pública: um relato de experiência. Florianópolis: Extensio: Revista Eletrônica de Extensão, n. 9, p. 43-56, 2010.

ZABALA, A. Enfoque globalizador e pensamento complexo: uma proposta para o currículo escolar. Porto Alegre: Artmed, 2002. 